\title{
Chile: Truly, madly, deeply
}

Cristóbal Palma Fotógrafo

La avidez de las revistas de arquitectura internacionales queda retratada en esta selección de publicaciones de un fotógrafo chileno. ¿Qué ven, o qué quieren ver hoy los extranjeros del remoto Chile? Dejando de lado romances y estereotipos, una lectura atenta de la prensa internacional devuelve un reflejo certero de la práctica local de la arquitectura.

DeEply / Cualquiera que haya hojeado el último número de la prestigiosa publicación japonesa $a+u$ dedicado a Chile (Chile: Deep South) probablemente terminó con la impresión que Chile es básicamente una región de increíbles paisajes (muchos de ellos apenas explorados), poblado por gemas arquitectónicas habitadas por un público de clase media-alta. Inevitablemente cualquier selección tiene un sesgo y establece un ángulo particular, que no necesariamente es representativo, pero sin duda esta no es la primera vez en que se utiliza este ángulo para hablar de Chile.

Además de la mirada romántica que tradicionalmente el hemisferio norte ha tenido del remoto Chile, también es cierto que durante los noventa hubo algunas imágenes de arquitectura chilena contemporánea que circularon con éxito en la prensa especializada internacional, y que seguramente condicionaron el ojo de los editores. Quizás fueron las primeras casas en la pradera que construyó Klotz en Tongoy y Maitencillo hace diez años las que abrieron el apetito voraz por el volumen en medio de la naturaleza, apetito que todavía determina muchas de las páginas internacionales sobre Chile; curiosamente, la obra de Klotz incluida en $a+u$ / Deep South es la única inserta en un contexto urbano denso. En los últimos años, este interés se ha renovado a través de las incontables publicaciones de la Casa Poli del estudio PvE en los acantilados de Coliumo. TRUuY / Quizás lo que más llama la atención con respecto a la selección de las obras en $a+u$ es que el 90\% de ellas fueran casas: pareciera que, ante ojos extranjeros, las actuales propuestas de arquitectura chilena no han logrado articularse apropiadamente con iniciativas públicas o clientes corporativos. En segundo lugar, que ninguna de las edificaciones estuviera situada en un contexto construido: no recuerdo haber visto ningún medianero (con la paradójica excepción del ya mencionado proyecto de Klotz). En tercer lugar, y excluyendo a PvE, que todos los arquitectos tengan sus oficinas en Santiago (y casi la mitad de ellos en el barrio Pedro de Valdivia Norte).

MADLY / En la mayor parte de los casos, la calidad de las obras en la selección de $a+u$ es indiscutible, pero es difícil creer que en Chile no exista mayor variedad en las tipologías o en los usos. En un país donde aún se permiten soluciones habitacionales de $25 \mathrm{~m}^{2}$ para familias completas, donde el mall es un modelo indiscutido y donde se prioriza la construcción de autopistas urbanas por sobre espacios públicos, sin duda la discusión dentro de la comunidad de los arquitectos (y las escuelas de arquitectura) debe ser un poco más variada a lo que $a+u$ nos muestra. Desgraciadamente, estando afuera es difícil enterarse.

Probablemente ya se ha establecido -por reiteración- que en Chile se pueden hacer proyectos interesantes en medio de paisajes extraordinarios. Lo que queda pendiente es una reacción de la prensa internacional a la posible existencia de buena arquitectura en contextos más problemáticos o exigentes. Ojalá el próximo número especial de alguna revista internacional dedicada a Chile esté lleno de Quintas Monroy, edificios como el de Puga en calle Bremen, pabellones universitarios en el centro de la ciudad como los de la Universidad Diego Portales, o edificios como el del Ministerio de Obras Públicas en Concepción: independientemente del mérito individual de estos ejemplos, es en este tipo de encargos donde realmente Chile hoy necesita a sus mejores arquitectos. ARQ
This selection on the work of a Chilean photographer shows current eagerness of international architectural press. What do foreigners look for, or what do they want to see from the remote Chile? Leaving stereotypes and romantic visions aside, a careful reading reflects accurately the state of local architecture practice.

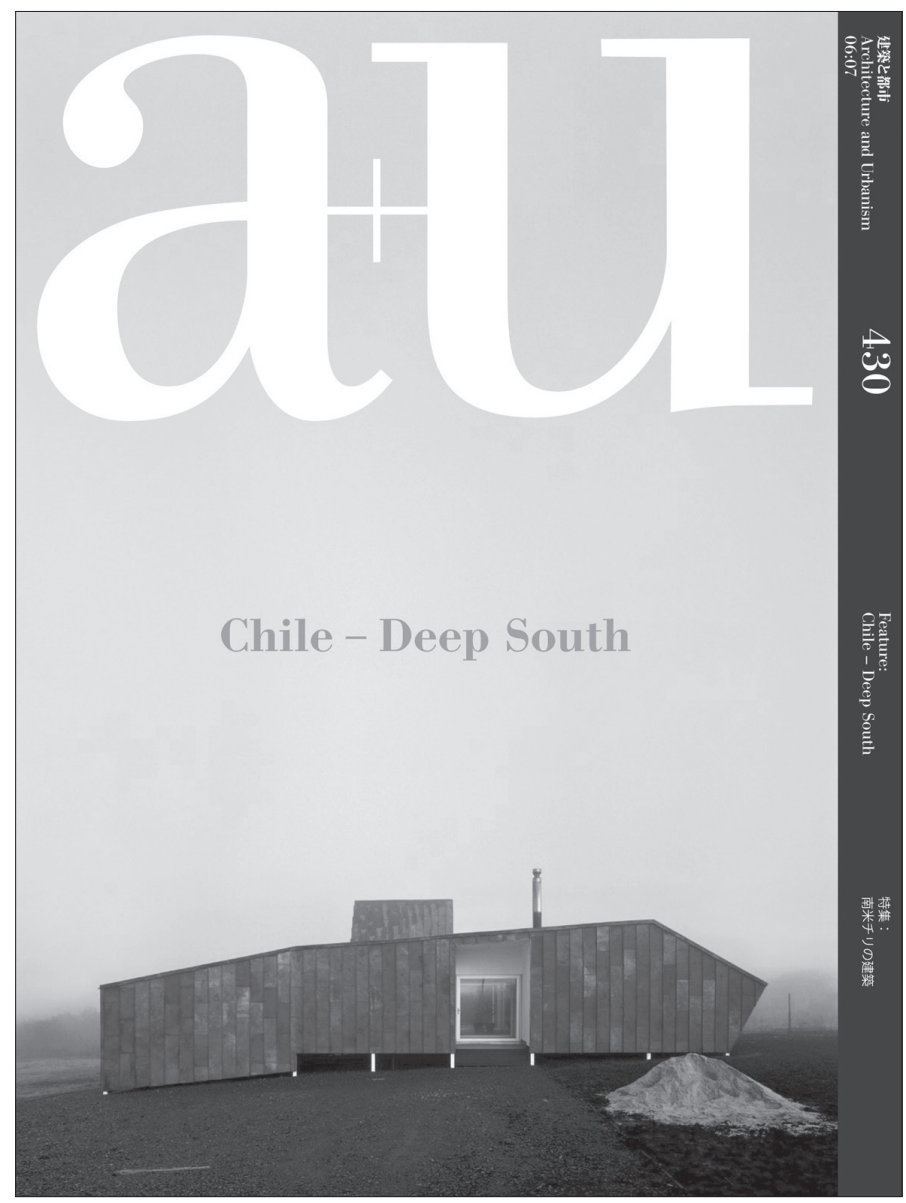

01 Chile Deep South - $a+u$ № 430, julio de 2006

02 Casa Poli, Coliumo. Pezo von Ellrichshausen

03 Casa Rivo, Valdivia. Pezo von Ellrichshaus

04 Casa Larrain, Los Vilos. Cecilia Puga

05 Casa Vodanovic, San Francisco de Los Andes. Cecilia Pug

06 Hotel Remota, Puerto Natales. Germán del Sol

07 Torres siamesas, Santiago. Alejandro Araven

08 Casa de cobre № 2, Talca. Smiljan Radic

09 Casa Punta Pite, Papudo. Smiljan Radic 

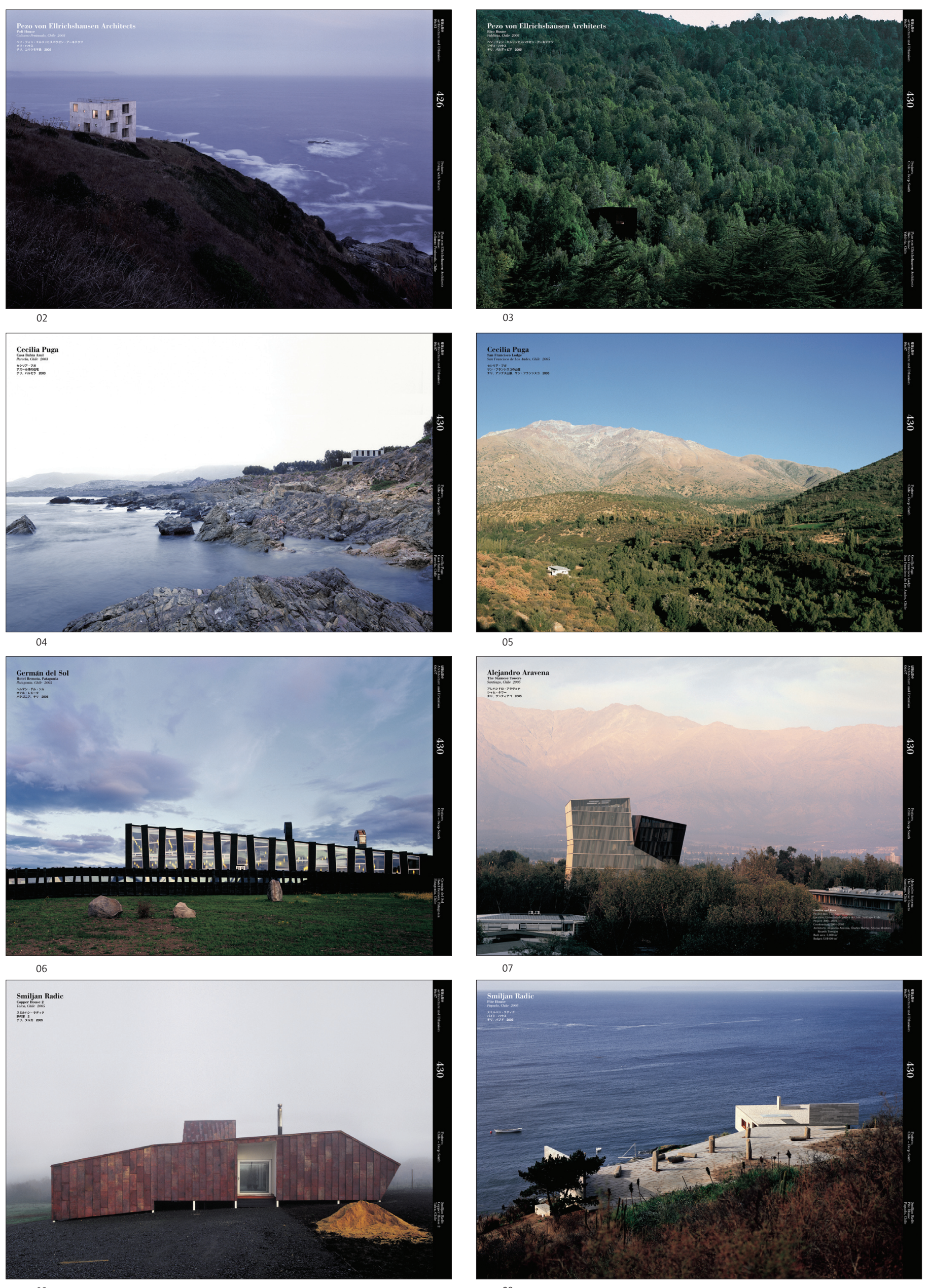

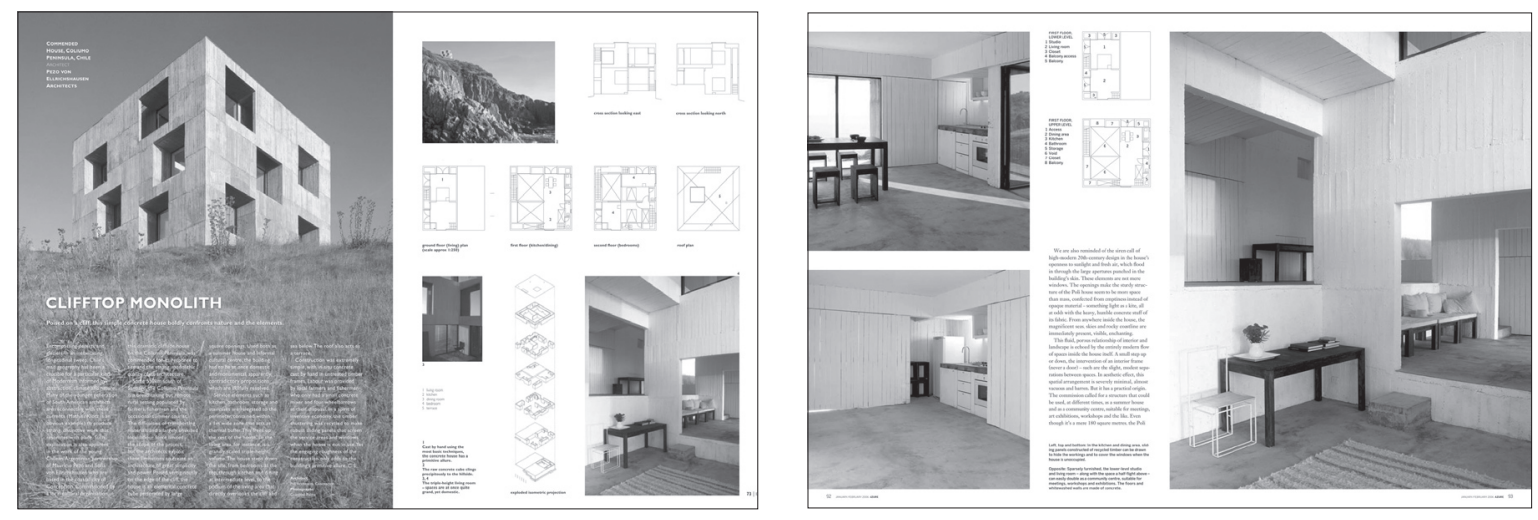

10
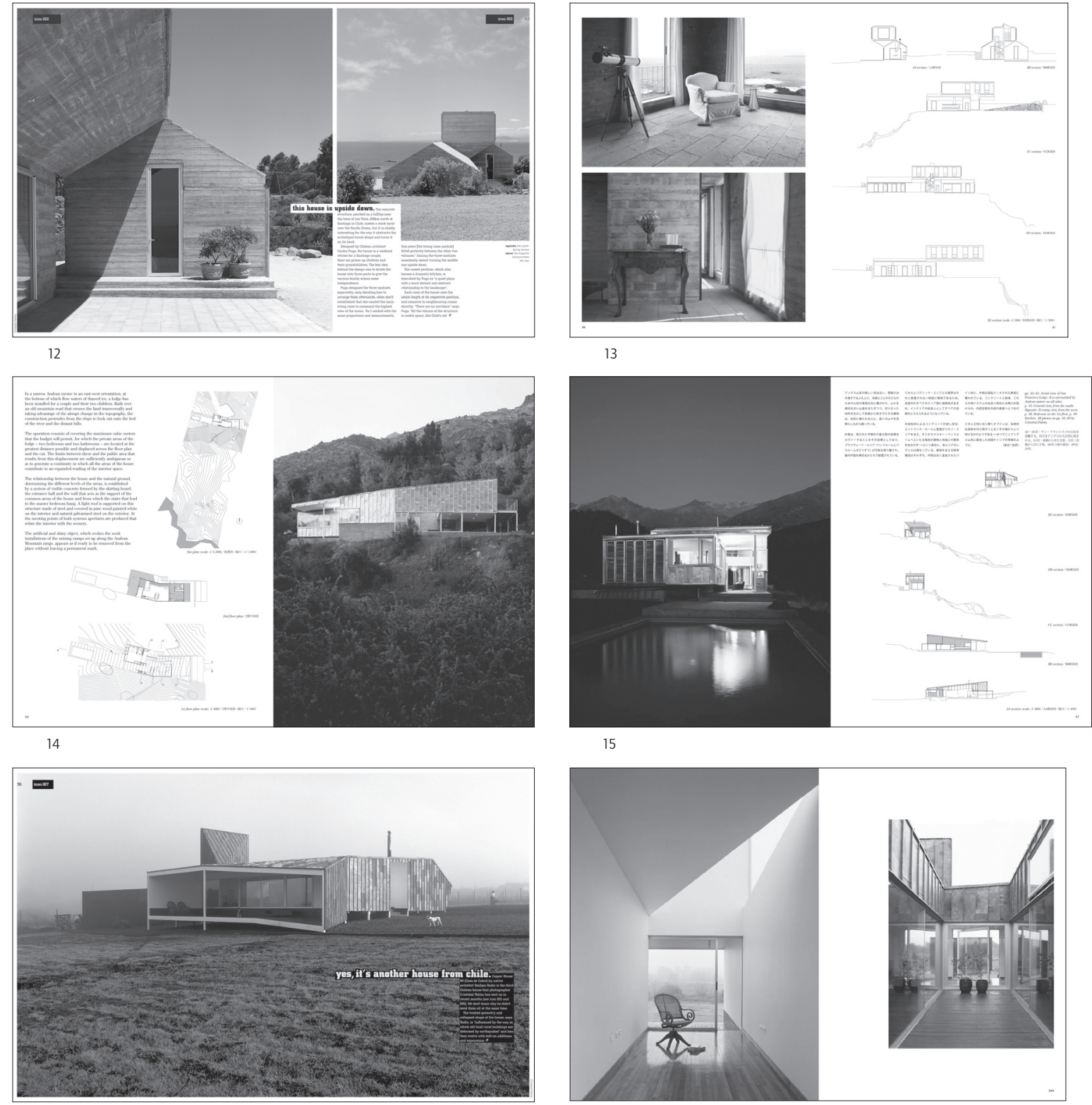

15
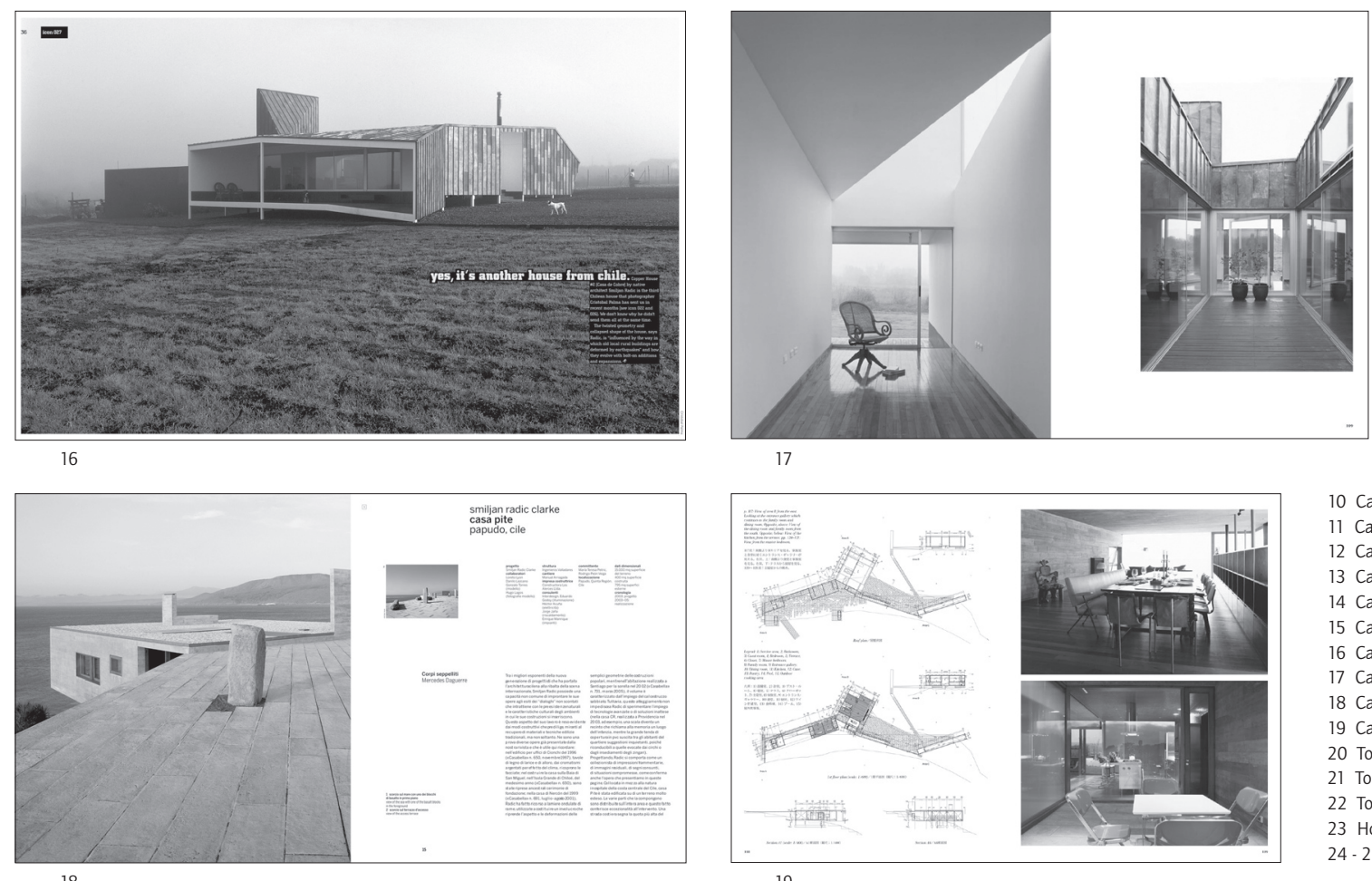

10 Casa Poli, PvE. The Architectural Review № 1306, diciembre de 2005 11 Casa Poli. Azure, enero de 2006

12 Casa Larrain, Cecilia Puga. Icon magazine № 22, abril de 2005 13 Casa Larrain. $a+u$ № 430 , julio de 2006

14 Casa Vodanovic, Cecilia Puga. $a+u$ № 430, julio de 2006 15 Casa Vodanovic. $a+u$ № 430, julio de 2006

16 Casa de cobre № 2, Smiljan Radic. Icon magazine № 27, septiembre de 2005 17 Casa de cobre № 2. $a+u$ № 430, julio de 2006

18 Casa Punta Pite, Smiljan Radic. Casabella № 746, julio de 2006

19 Casa Punta Pite. $a+u$ № 430, julio de 2006

20 Torres Siamesas, Alejandro Aravena. $a+u$ № 430, julio de 2006

21 Torres Siamesas. Casabella № 747, septiembre de 2006

22 Torres Siamesas. Icon magazine № 37 , julio de 2006

23 Hotel Remota, Germán del Sol. Azure, junio de 2006

24 - 25 Hotel Remota. Icon magazine № 35, mayo de 2006 

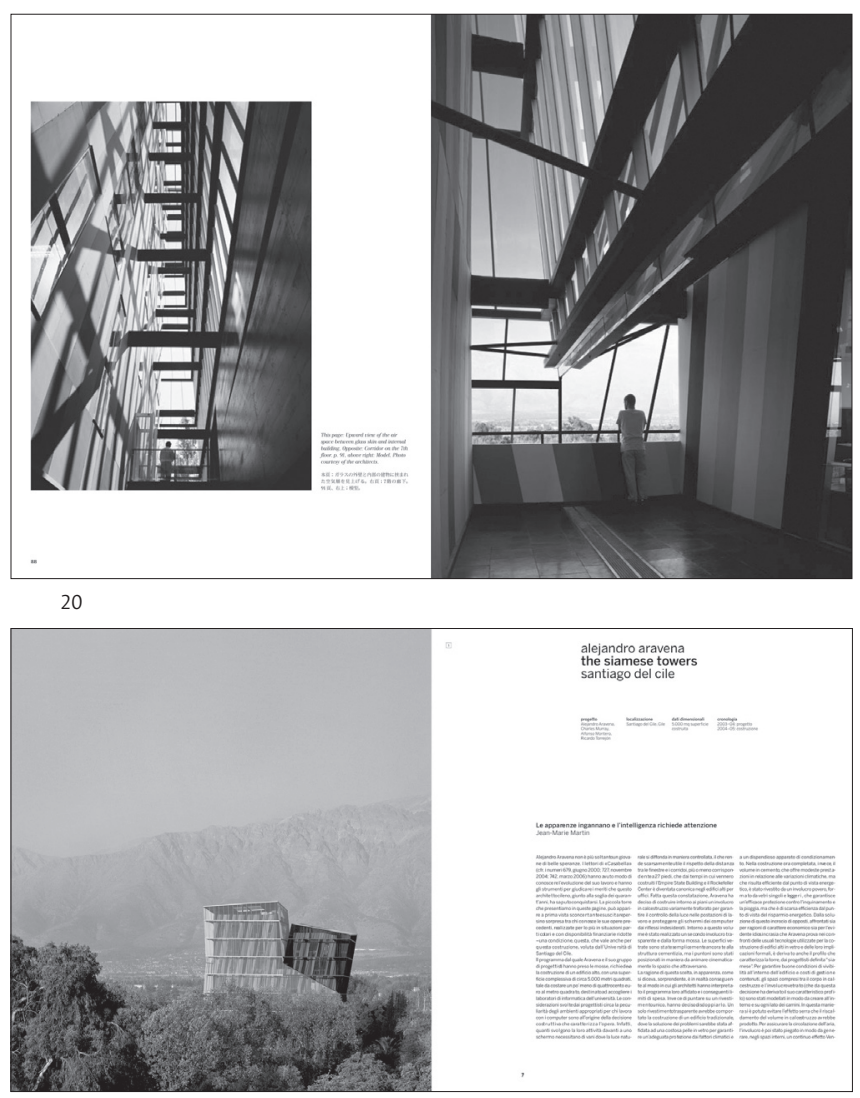

21

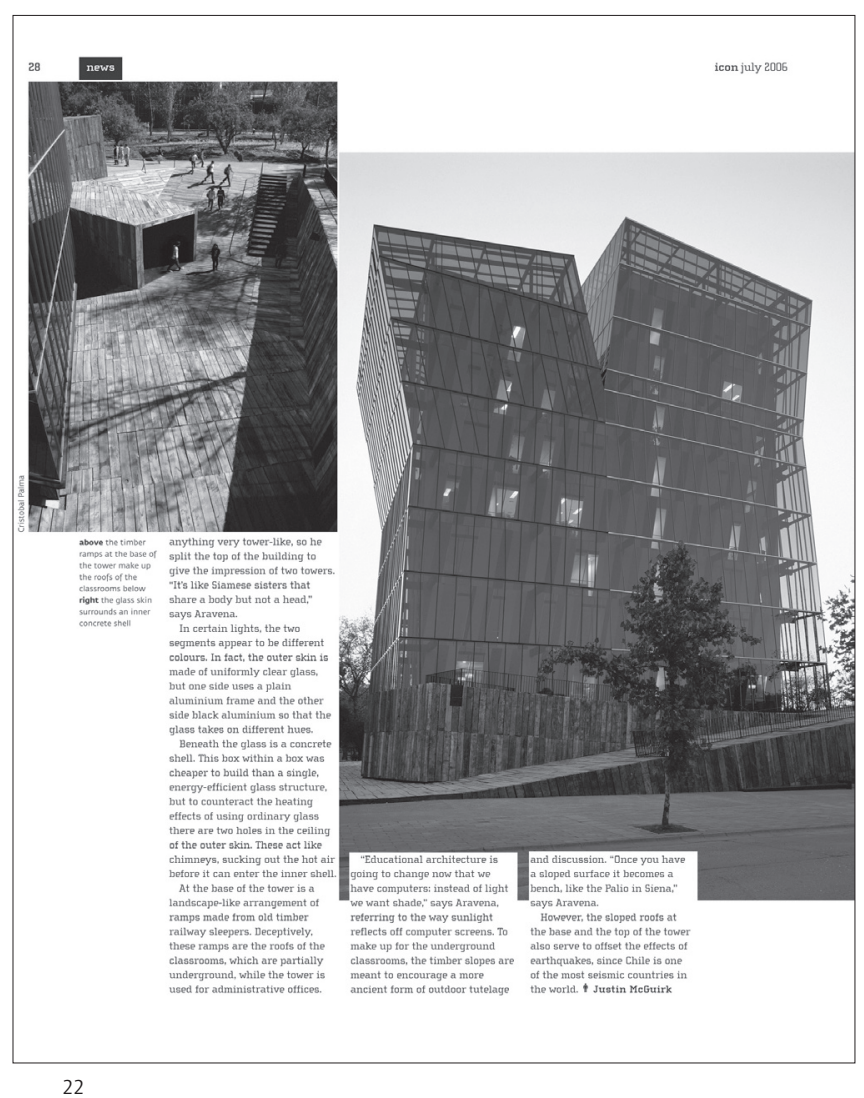

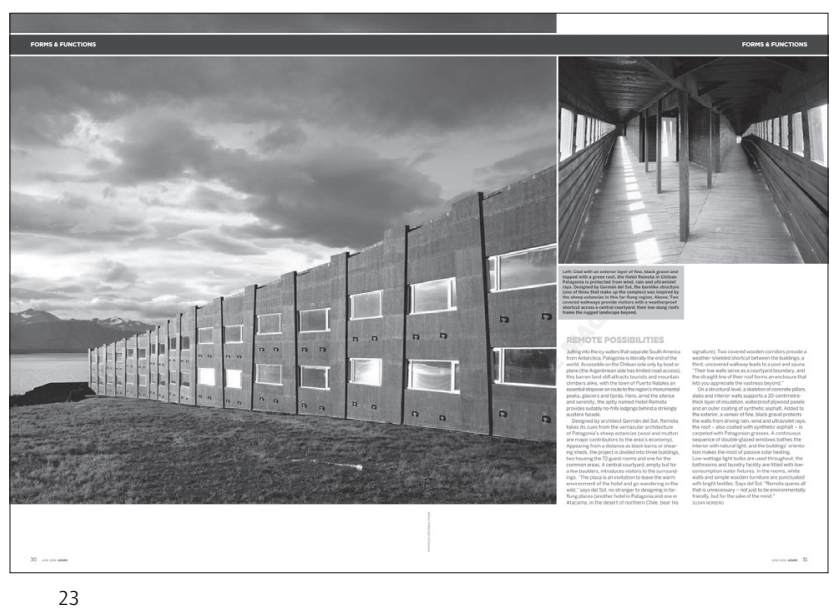
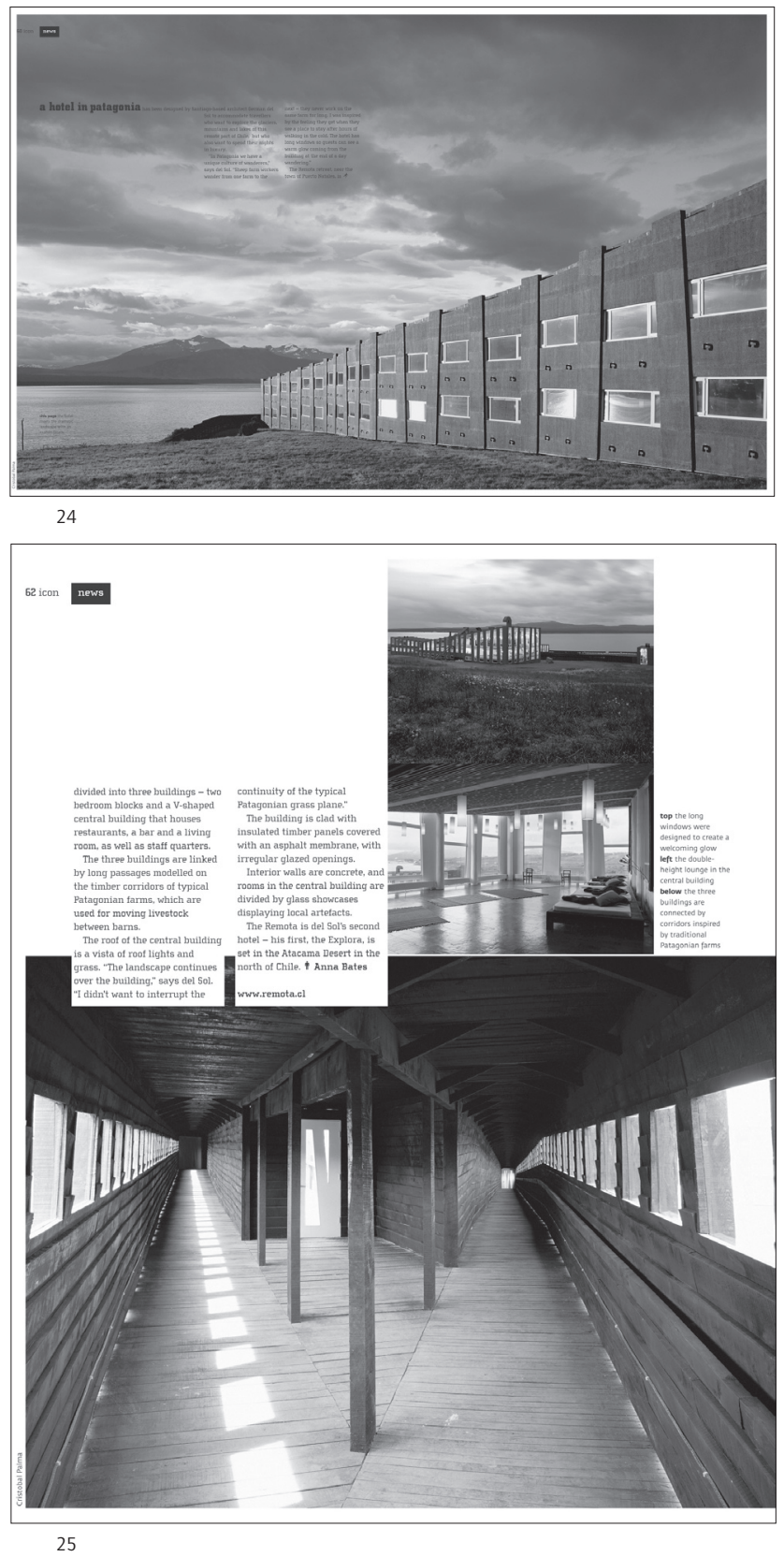